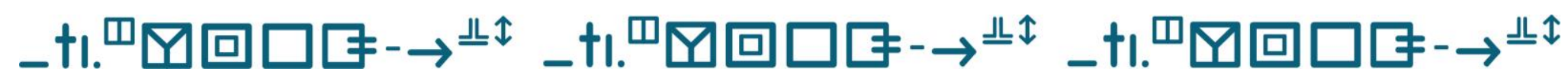

\section{Memórias, histórias e narrativas da liderança surda na luta pela cidadania: da semente plantada à árvore crescida ${ }^{1}$}

Memories, stories, and narratives from the deaf leadership in the fight for citizenship: from the planted seed to the grown tree

\footnotetext{
(iD) Ana Luiza Paganelli Caldas

Universidade Federal do Rio Grande do Sul (UFRGS), Porto Alegre, Rio Grande do Sul, Brasil.

Universidade Federal de Pelotas (UFPEL), Pelotas, Rio Grande do Sul, Brasil. anacrespa2012@gmail.com
}

Resumo: Neste artigo, narro a história dos acontecimentos de 1999, a partir das memórias registradas em fotos e depoimentos, que representam um marco inicial do movimento da comunidade surda que lutou para o reconhecimento da Língua de Sinais Brasileira, a Libras. Antigamente, nossas mãos eram atadas. Agora, temos mãos livres. E com as mãos livres nosso pensamento se libertou. Apresento algumas referências que construíram nossa história e associo a ideia de uma semente de árvore que no solo escuro adquire forças para desabrochar e crescer, espalhando seus frutos. Considero que ainda existe e sempre existirá luta no campo da Educação de Surdos e das Políticas Públicas para surdos. Convido a todos para continuarmos semeando nossa história, realizando todos os anos a passeata nacional no dia 26 de setembro.

\footnotetext{
${ }^{1}$ Texto traduzido de Libras para o português por Pauini Barcellos Sanchez.
} 
Palavras-chave: Liderança surda; Surdo cidadão; História surda.

Abstract: In this paper, I narrate the history of the events of 1999, from memories recorded in pictures and testimonials, which represent an initial mark in the movement of the deaf community that fought for the recognition of the Brazilian Sign Language, Libras. In the past, our hands were tied. Now, our hands are free. And with our hands free, our thoughts were liberated. I present some references that built our history and associate the idea to the seed of a tree that in the dark soil acquires enough strength to bloom and grow, spreading its fruits. I consider that there still is, and there will always be, struggle in the field of Deaf Education and Public Policies for the deaf. I invite one and all to continue sowing our history every year in the national march on September 26.

Keywords: Deaf leadership; Deaf citizen; Deaf history.

Submetido em 08 de junho de 2021.

Aceito em 17 de setembro de 2021.

Publicado em 14 de dezembro de 2021. 


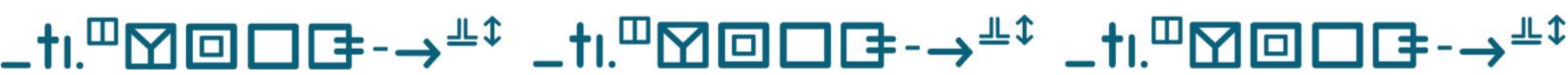

Memórias, histórias e narrativas da liderança surda na luta pela cidadania: da semente plantada à árvore crescida

Ana Luiza Paganelli Caldas

\section{Arando a terra}

Iniciamos nossa luta pelo reconhecimento da cidadania surda muito antes de 1999. Nas escolas da nossa geração, nem se pensava em educação bilíngue porque ainda engatinhávamos nos assuntos relacionados às políticas públicas para a comunidade surda e, apesar de já existirem escolas bilíngues para surdos, a maioria de nós era educada nos métodos oralistas da inclusão escolar.

Eu estava inserida em uma educação tradicional onde era mera copista, não sabia realmente o significado das palavras e apenas as decorava. [...] Naquela época estava inserida numa escola dita inclusiva, porém os professores não sabiam nada sobre surdez (CALDAS, 2012, p. 58).

Com a criação da Federação Nacional de Educação e Integração dos Surdos (FENEIS), alguns anos antes, conquistamos um empoderamento comunitário, já que esta instituição é, até hoje, a representação máxima dos interesses da comunidade surda perante os governantes. Com o incentivo da FENEIS, começamos a realizar encontros para debater sobre os assuntos da educação de surdos e das políticas linguísticas que dizem respeito à nossa comunidade.

Assim, uma das nossas lideranças, a Gladis Perlin, que foi a primeira surda brasileira a obter o título de doutorado (1999-2003), estabeleceu parceria com o grupo de pesquisa da Universidade Federal do Rio Grande do Sul chamado Núcleo de Pesquisa em Políticas Educacionais para Surdos (NUPPES), promovendo cursos para instrutores de Libras a fim de estimular a educação na nossa língua nativa. Mas ainda estávamos longe do sonho ideal de uma pedagogia surda em uma escola de surdos. 


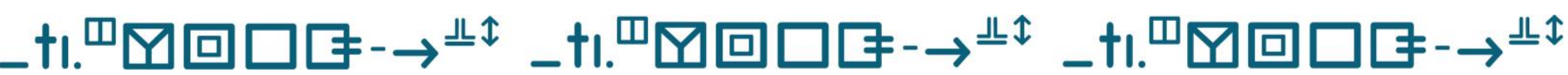

Memórias, histórias e narrativas da liderança surda na luta pela cidadania: da semente plantada à árvore crescida

Ana Luiza Paganelli Caldas

Fui conversar e combinar o roteiro com a intérprete de Libras Maria Cristina. Combinamos a primeira reunião da comissão na chácara em Sapiranga/RS da família do meu marido Augusto Schallenberger. Combinávamos de nos encontrar também na sede da FENEIS/RS e conversávamos sobre como organizar para fazer a passeata. A tarefa era compor comissões de organização para a passeata e elaborar o documento que ficou com o título "A educação que nós surdos queremos" (FENEIS, 1999). A foto (foto 1) a seguir é da nossa reunião de abertura.

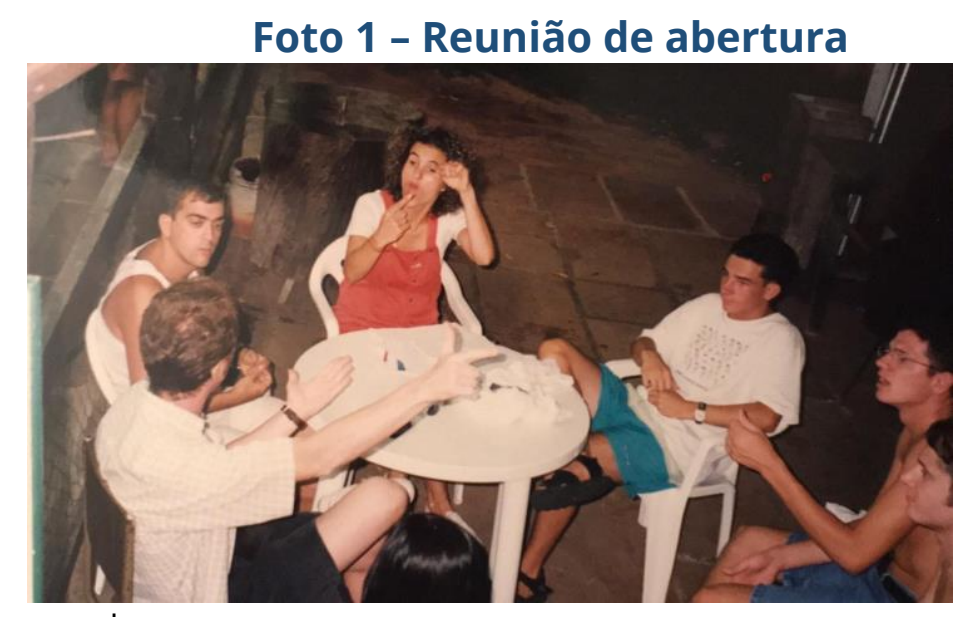

Fonte: Arquivo pessoal.

Descrição da imagem: foto tirada em Sapiranga/RS, em 1998, em nossa reunião de abertura para organizar o evento. Na foto, estão Eduardo Gheller Mörschbächer de costas, ao lado estão Carlos Roberto Martins, eu, Gustavo Perazzolo, Leandro Golin e Luis Gustavo junges (In memoriam).

$$
\begin{aligned}
& \text { Lembro que teve um momento que eu estava propondo uma } \\
& \text { solução de credenciamento, pagamento até emissão de } \\
& \text { certificado. } \quad[. . .] \quad \text { ajudei ideias, aconselhamento. } \\
& \text { (MÖRSCHBÄCHER, 2019, informação verbal). }
\end{aligned}
$$

Nosso grupo foi integrado por Carlos Roberto Martins, Eduardo Gheller Mörschbächer, Gustavo Perazzolo, Leandro Golin, Luis Gustavo Junges (In memoriam) e Maria Cristina Pires Pereira (Foto 2). 


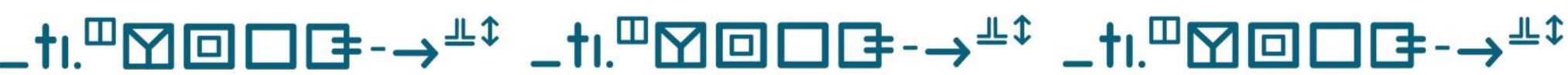

Memórias, histórias e narrativas da liderança surda na luta pela cidadania: da semente plantada à árvore crescida

Ana Luiza Paganelli Caldas

Foto 2 - Passeata pela Educação de Surdos em Porto Alegre/RS (1999)

Fonte: Arquivo pessoal.

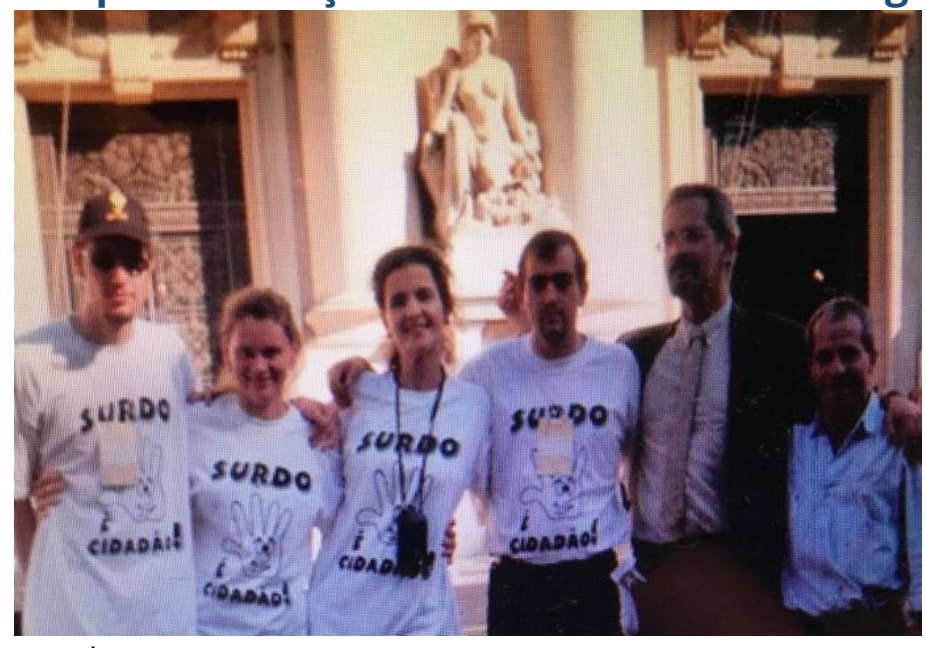

Descrição da imagem: foto tirada em frente ao Palácio Piratini em Porto Alegre/RS, no ano de 1999, durante a passeata pela educação que nós surdos queremos com a camiseta SURDO É CIDADÃO. Na foto, estão Luis Gustavo Junges (In memoriam), Maria Cristina Pires Pereira, eu, Carlos Roberto Martins, Carlos Alberto Goés e Carlos Silva.

Lembro como começou movimento aqui no RS muito devagar, não tinha luta. Ana Luiza me chamou queria saber como lutar, todos precisam aprender Libras, precisamos reclamar. Eu disse: Calma, eu penso que você deve fazer comissão para fazer passeata, debater ideias, fazer faixas, mas sozinha não. Deve fazer comissão, escolher pessoas responsáveis, você aceita? Ela aceitou e organizou. Foi ótimo, maravilhoso. Eu fiquei muito feliz. A passeata foi linda. Antigamente era difícil conseguir chamar, mandávamos carta, trabalhávamos muito, não era fácil a comunicação, não era fácil! Ela me pediu para avisar na rádio, eu coloquei as mãos na cabeça, chamei Joao Motta, e perguntei, por favor, você conhece como divulgar na rádio? Celular não tinha, televisão era difícil, rádio foi mais fácil, jornal a divulgação foi pouca, e divulgamos em família. Agora é mais fácil. Foi ótimo a passeata muita gente, não foi pequena, foi enorme. Eu vi, estava em pé no alto e vi aquela multidão [Foto 3]. Emocionante, fico feliz, orgulhoso e emocionado. O governador Olívio aceitou nos encontrar. (GOÉS, 2019, informação verbal). 


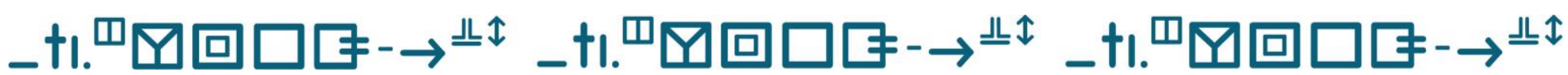

Memórias, histórias e narrativas da liderança surda na luta pela cidadania: da semente plantada à árvore crescida

Ana Luiza Paganelli Caldas

Foto 3 - Passeata pela Educação de Surdos em Porto Alegre/RS (1999)

Fonte: Arquivo pessoal.

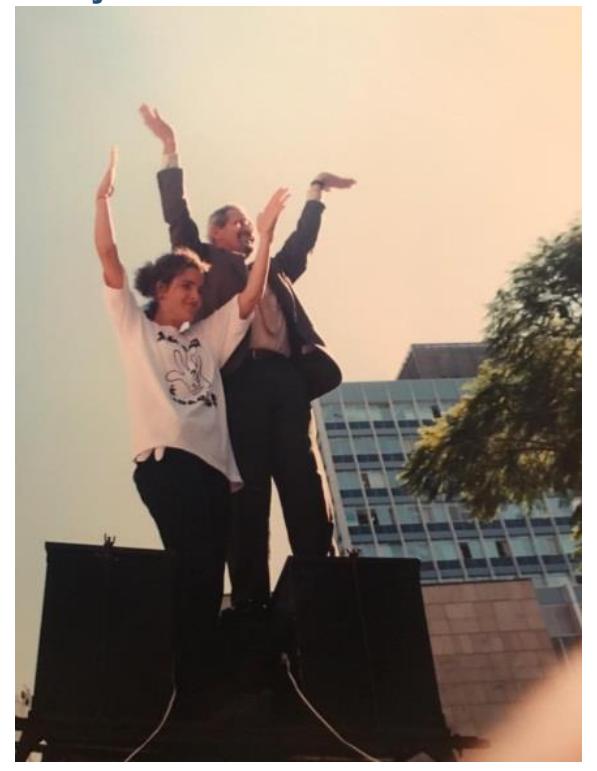

Descrição da imagem: foto tirada na rua em Porto Alegre/RS, no ano de 1999, em cima do carro de som durante a passeata pela educação que nós surdos queremos. Na foto, estão eu e Carlos Alberto Goés.

A comunidade surda se organizou para o evento que reuniu mais de mil e quinhentas pessoas na passeata em Porto Alegre, no ano de 1999, para entregar nossa carta-manifesto sobre a educação que nós surdos queremos ao então Governador Olívio Dutra (Foto 4).

Foto 4 - Entrega da carta-manifesto para o governador Olívio Dutra em Porto Alegre/RS (1999)

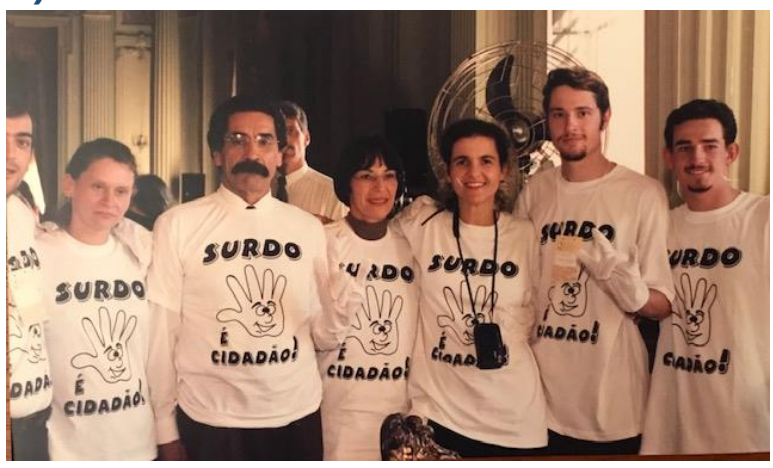

Fonte: Arquivo pessoal.

Descrição da imagem: foto tirada dentro do Palácio Piratini em Porto Alegre/RS, no ano de 1999, durante a entrega da carta-manifesto pela educação que nós surdos queremos ao Governador Olívio Dutra. Na foto, estão Carlos Roberto Martins, Maria Cristina Pires Pereira, 


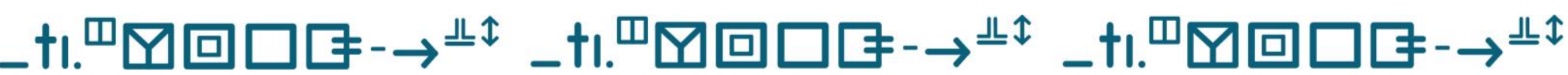

Memórias, histórias e narrativas da liderança surda na luta pela cidadania: da semente plantada à árvore crescida Ana Luiza Paganelli Caldas

para solicitação de uso de via pública e com a Brigada Militar (BM) para a escolta com motos.

- Além disto, fiquei encarregada do desenho da camiseta da passeata, que podemos ver na foto a parte da frente (Foto 5). Infelizmente, acho que a arte foi perdida, pois não tenho mais o desenho da parte posterior.

- A passeata foi um marco importantíssimo na história dos surdos brasileiros, mas não a vejo sendo muito mencionada, infelizmente. $O$ documento que a comunidade surda elaborou se tornou uma "referência para a elaboração de um decreto que iria regulamentar a Lei de Libras no Brasil, posteriormente" (FERNANDES; MOREIRA, 2014, p. 56), ainda assim o movimento é pouco citado. Por exemplo, encontrei uma monografia que cita outra pessoa como responsável pela passeata (FERRAZ, 2009) e não faz nenhuma menção à comissão do Rio Grande do Sul que teve tanto trabalho na organização desta manifestação.

- Um fato marcante foi na cerimônia de encerramento do congresso em que nem citaram, ao menos, a coordenadora da passeata. Nos sentimos muito orgulhosos de termos conseguido sucesso, enchendo as ruas de Porto Alegre com escolas de surdos, pessoas surdas e ouvintes de diversos países, mas nos sentimos um pouco decepcionados pela falta de reconhecimento. Enfim, acontece... (PEREIRA, 2019, informação verbal).

\section{Foto 5 - Maria Cristina Pires Pereira na Passeata pela Educação de Surdos em Porto Alegre/RS (1999)}

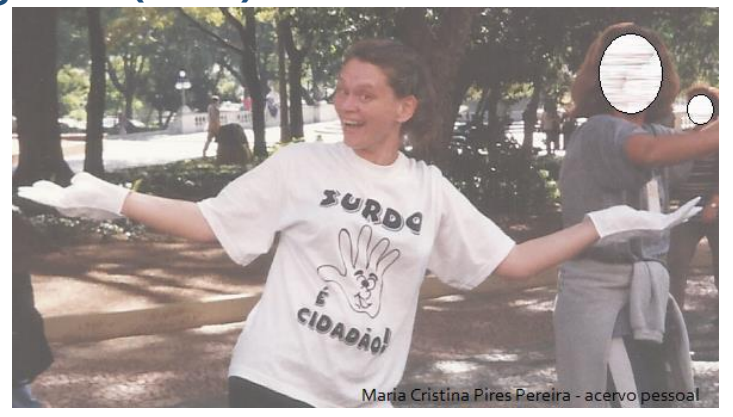

Fonte: Arquivo pessoal.

Descrição da imagem: foto tirada na Praça da Matriz em Porto Alegre, no ano de 1999, durante a passeata. Na foto, está Maria Cristina Pires Pereira.

Como membro da comissão da passeata, a Maria Cristina ligava ao telefone me apoiando para marcar dia e hora na Assembleia Legislativa. 


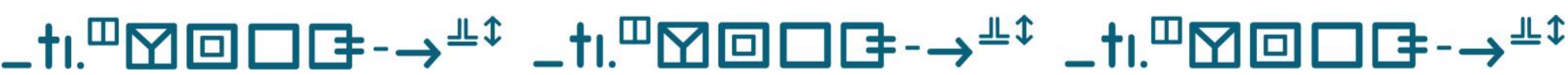

Memórias, histórias e narrativas da liderança surda na luta pela cidadania: da semente plantada à árvore crescida

Ana Luiza Paganelli Caldas

Porém, no dia agendado, ela tinha outro compromisso da comissão. Então, eu procurei o NUPPES/UFRGS para solicitar apoio de intérprete de Libras e as estudantes de doutorado pelo NUPPES/UFRGS, Márcia Lunardi e Liliane Giordani, apoiaram como intérpretes de Libras em reunião com a Maria do Rosário, na época Deputada Estadual, para agendar a participação do Governador Olívio Dutra, o fechamento das ruas para a passeata e a divulgação nas mídias e jornais (Foto 6).

\section{Foto 6 - Reunião com a deputada estadual Maria do Rosário na Câmara dos Deputados de Porto Alegre/RS (1999)}

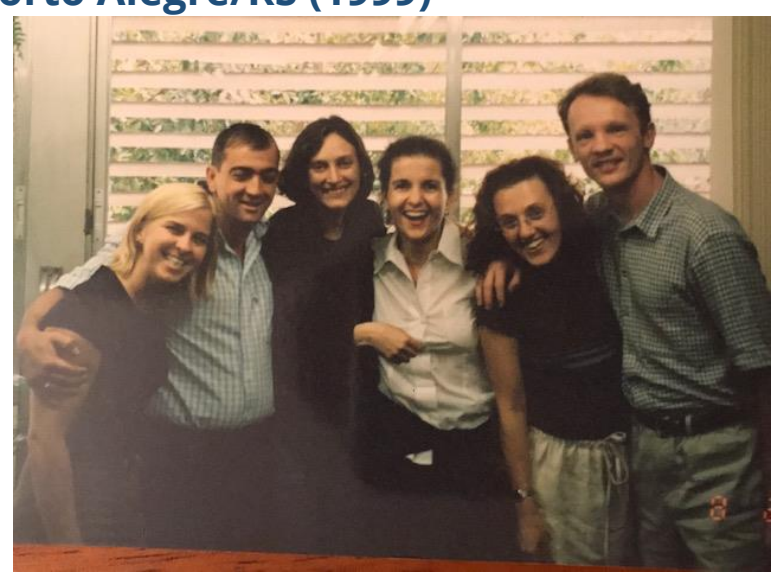

Fonte: Arquivo pessoal.

Descrição da imagem: foto tirada na Câmara dos Deputados de Porto Alegre, no ano de 1999, em reunião na sala da deputada estadual Maria do Rosário. Na foto, estão Liliane Giordani, Carlos Roberto Martins, Deputado Estadual, Maria do Rosário, Eu, Márcia Lunardi e Eduardo Gheller Mörschbächer.

Participaram estudantes das escolas, famílias, professores de surdos, professores surdos, intérpretes de Libras, estudantes de Universidades e Faculdades, surdos estrangeiros das Américas do Norte, Central e Latina, além de europeus.

A comunidade surda é feita de pessoas surdas, mas também de pessoas que se movem dentro e fora da vida das pessoas surdas de forma importante - intérpretes, pessoas que trabalham em agências de Serviço Social, professores, outros 


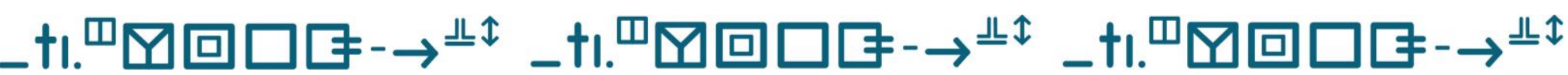

Memórias, histórias e narrativas da liderança surda na luta pela cidadania: da semente plantada à árvore crescida

Ana Luiza Paganelli Caldas

profissionais, amigos ouvintes que trabalham muito próximos de pessoa surda (PADDEN, 1993, p. 5 apud THOMA e KLEIN, 2010, p. 110).

Nosso grupo liderou a organização, preparando a passeata e a comissão de Luis Gustavo Junges (In memoriam) trouxe as camisetas "SURDO É CIDADÃO!". Leandro Golin teve a ideia de trazer luvas brancas para chamar atenção para a comunicação com as mãos vivas e a faixa da FENEIS: "INFORMAÇÃO. TODOS NÓS TEMOS DIREITO!". Estes foram alguns dos símbolos da passeata como mostra a foto abaixo (Foto 7).

\section{Foto 7 - Luvas brancas, camiseta "SURDO É CIDADÃO!" e faixa da FENEIS na Passeata pela Educação de Surdos em Porto Alegre/RS (1999)}

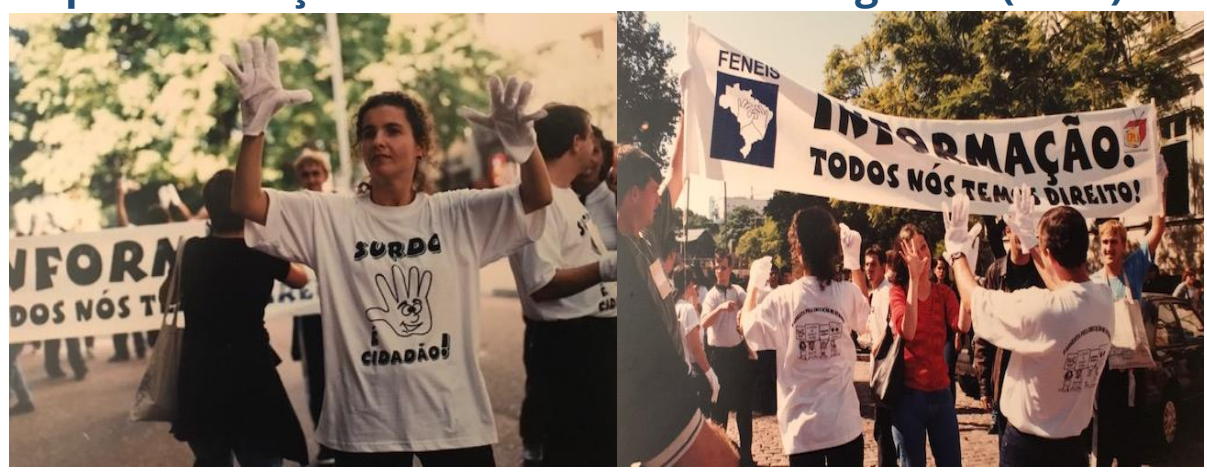

Fonte: Arquivo pessoal.

Descrição da imagem: foto tirada na rua em Porto Alegre, no ano de 1999, durante a passeata mostrando as luvas brancas para mostrar as mãos vivas, a camiseta "SURDO É CIDADÃO!" e a faixa da FENEIS com os dizeres "INFORMAÇÃO. TODOS NÓS TEMOS DIREITO", símbolos da campanha pela educação que nós surdos queremos. Na foto, estão eu e as pessoas na passeata.

Lembro pouco... 1999 faz muitos anos. A passeata quem liderou foi Ana Luiza convidando o grupo da comissão. Eu lembro que as camisetas, eu acho, quem trouxe foi o Luis Gustavo (In memoriam). A comissão era tu (Ana Luiza), eu, Augusto, Cristina, Gustavo, o grupo que organizou a passeata. Lembro que a mãe e o pai do Gustavo auxiliaram no trabalho com as camisetas para nos vestirmos iguais até chegar ao Olívio Dutra e entregar o documento. (MARTINS, 2019, informação verbal). 


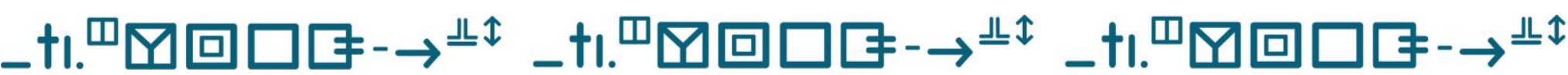

Memórias, histórias e narrativas da liderança surda na luta pela cidadania: da semente plantada à árvore crescida

Ana Luiza Paganelli Caldas

Construímos também o Pré-Congresso, que reuniu diversos grupos de surdos de várias regiões. Gladis Perlin já havia começado o doutorado e organizou, junto com outros professores surdos, o documento encaminhando as propostas para debate entre a comunidade surda presente no Pré-Congresso.

A finalidade desse pré-congresso foi criar um espaço de discussão dos surdos, ou seja, um espaço propositivo de temáticas de interesse do povo surdo, tendo como ênfase discutir e tomar posição com relação às Identidades Surdas, à Cultura Surda e à Educação de Surdos (THOMA; KLEIN, 2010, p. 111).

Nossa equipe da comissão estava no Pré-Congresso em que construímos, coletivamente, um documento oficial contendo nossas reivindicações políticas, linguísticas e educacionais. A vice-diretora surda da escola para surdos Dr. Reinaldo Coser, de Santa Maria, aproveitou a oportunidade para participar da passeata com o grupo e apresentou as propostas da escola.

Aconteceu na cidade de Porto Alegre, no Rio Grande do Sul, no Salão de Atos da Reitoria da UFRGS, nos dias de 20 a 24 de abril de 1999, o V Congresso Latino-Americano de Educação Bilíngue para Surdos, em que mestrandos e doutorandos pelo NUPPES/UFRGS foram organizadores. Também finalizamos a redação da nossa carta.

O NUPPES - Núcleo de Pesquisa em Políticas Educacionais para Surdos criado em 1997 junto ao Programa de PósGraduação em Educação da Universidade Federal de Rio Grande do Sul/UFRGS foi um grupo muito importante à comunidade surda, pois possibilitou o ingresso de surdos nos cursos de mestrado e doutorado, como também, produziu novos olhares sobre as pesquisas no campo da educação de surdos. [...] Esse investimento de pesquisa no campo da 


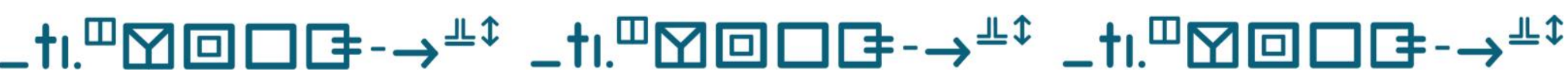

Memórias, histórias e narrativas da liderança surda na luta pela cidadania: da semente plantada à árvore crescida

Ana Luiza Paganelli Caldas

educação de surdos contribuiu para ampla divulgação e visibilidade das lutas sociais, educacionais e políticas das comunidades surdas (DALL'ALBA, 2013, p. 23).

Conquistamos espaços e outros Estados se uniram nessa construção política, pedagógica e social. Vieram pessoas do Rio de Janeiro, Fortaleza, Recife, Pará, Alagoas etc. Já tínhamos, em Porto Alegre, segundo grau para surdos na escola Concórdia, uma conquista resultado de lutas pela comunidade surda gaúcha. Antes, a Universidade Luterana do Brasil (ULBRA) era a única instituição de ensino superior com intérpretes de Libras. No Brasil, não havia acessibilidade. A ULBRA foi uma das pioneiras, mas ainda assim a carga horária era insuficiente para a comunidade surda que foi aumentando no ensino superior.

Finalizado o V Congresso Latino-Americano de Educação Bilíngue para Surdos, saímos em passeata até a Assembleia Legislativa para formalizar a entrega do documento redigido nos eventos acima citados e oficializar nossas reivindicações de melhoria e qualificação das políticas públicas para o cidadão surdo. Fico emocionada ao lembrar a fila enorme com aproximadamente 1.500 pessoas integradas à comunidade surda.

Saímos da reitoria da Universidade Federal do Rio Grande do Sul (UFRGS) em direção à faculdade de Engenharia na Rua Sarmento Leite, passamos para a Avenida João Pessoa e continuamos a caminhada pela Avenida Salgado Filho. Subimos pela Avenida Borges de Medeiros até a Rua Riachuelo, chegando na Praça da Matriz, que é em frente à Assembleia Legislativa (Foto 8). 


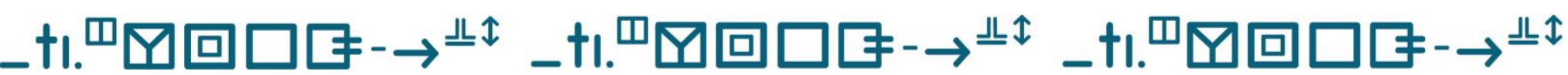

Memórias, histórias e narrativas da liderança surda na luta pela cidadania: da semente plantada à árvore crescida

Ana Luiza Paganelli Caldas

Dutra, do Estado do Rio Grande do Sul, recebeu o documento sobre "A educação que nós surdos queremos", com o compromisso de encaminhá-lo ao Ministério da Educação (MEC), integrando nossa pauta ao debate político em Brasília (Foto 10).

\section{Foto 10 - Entrega do documento "A educação que nós surdos queremos" em Porto Alegre/RS (1999)}

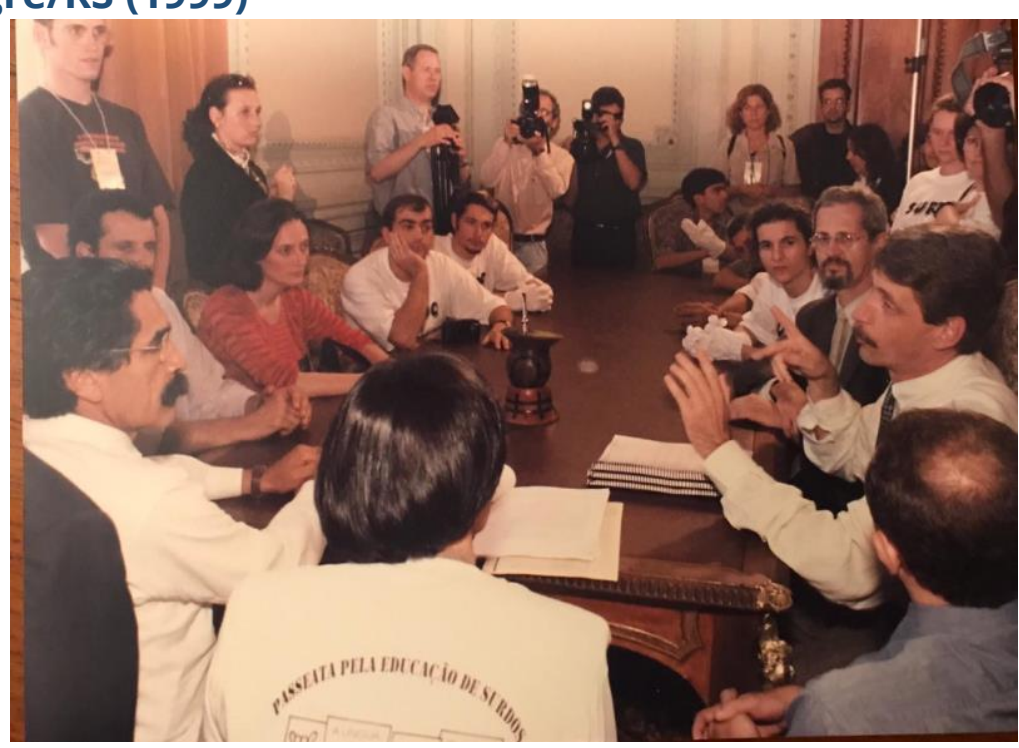

Fonte: Arquivo pessoal.

Descrição da imagem: foto tirada no salão do Palácio Piratini em Porto Alegre, no ano de 1999, durante a entrega do documento "A educação que nós surdos queremos". Na foto, estão à esquerda das pessoas de costas o Governador Olívio Dutra, o Vereador João Motta, a Deputada Estadual Maria do Rosário, Carlos Roberto Martins e Luis Gustavo Martines. Em pé estão Ricardo Goés, Márcia Lunardi e membros da empresa americana DawnSing Press. À direita das pessoas de costas estão sentados Antônio Abreu, Carlos Alberto Goés, eu e atrás de mim, de pé, a Maria Cristina Pires Pereira. As outras pessoas são da imprensa.

O governador Olívio Dutra foi presenteado com a camiseta "Surdo é cidadão!" e com as luvas brancas que chamam a atenção para as mãos vivas (Foto 11). Também receberam a camiseta e as luvas a secretária de educação e a deputada estadual Maria do Rosário, como está registrado na foto. 


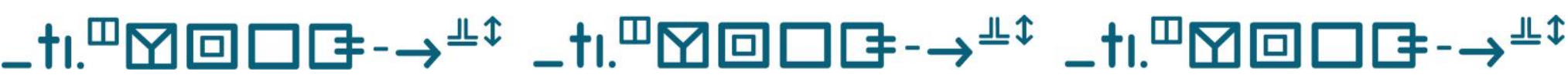

Memórias, histórias e narrativas da liderança surda na luta pela cidadania: da semente plantada à árvore crescida

Ana Luiza Paganelli Caldas

Foto 11 - No saguão do Palácio Piratini em Porto Alegre/RS (1999)

Fonte: Arquivo pessoal.

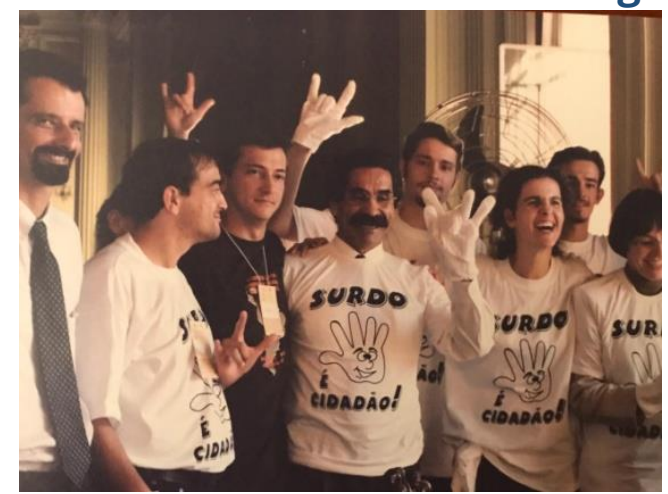

Descrição da imagem: foto tirada no saguão do Palácio Piratini em Porto Alegre, no ano de 1999, com o Governador Olívio Dutra vestindo o seu presente: a camisa SURDO É CIDADÃO! Na foto, estão o Vereador João Motta, Carlos Roberto Martins, Marcelo Lemos, Governador Olivio Dutra, eu e atrás de mim Luis Gustavo Junges (In memoriam), Gustavo Perazzolo e ao lado a Secretária de Educação.

Esse evento fortificou o reconhecimento do povo surdo no Brasil e, a partir dele, foi promulgada a Lei $n^{\circ}$. 11.405, de 31 de dezembro de 1999, que dispõe sobre a regulamentação da Libras em âmbito estadual.

Muito importante agradecer ao povo que participou da Passeata pela Educação de Surdos em Porto Alegre/RS (1999). Tivemos dificuldades, antes não tinha internet e não tinha celular. O esforço do intérprete nessa luta é reconhecido. Registro a minha admiração quando vi as faixas e as camisetas usadas na passeata.

Nossa árvore cresceu e poucos anos depois deu frutos. Foi publicada a Lei Federal $n^{\circ}$ 10.436/2002, que reconhece a Libras como língua da comunidade surda, e também o Decreto $n^{\circ} 5.626 / 2005$, que regulamenta essa lei e solidifica nossos direitos linguísticos, entre outras legislações recentemente publicadas. Conquistamos um empoderamento político para cumprir nossos direitos de cidadãos surdos brasileiros usuários da Libras. 


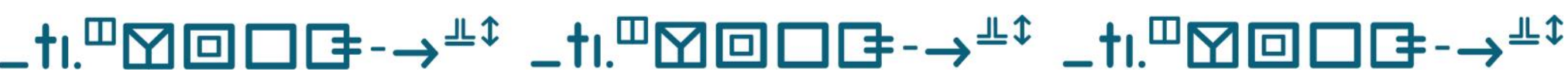

Memórias, histórias e narrativas da liderança surda na luta pela cidadania: da semente plantada à árvore crescida

Ana Luiza Paganelli Caldas

\section{Regando a árvore}

Dez anos depois, fui convidada pela Tatiana Bolivar Lebedeff, que estava na equipe do Grupo Interdisciplinar de Pesquisa em Educação de Surdos (GIPES) e era professora da Universidade do Pampa (UNIPAMPA), para palestrar em Santana do Livramento sobre dez anos da carta "A educação que nós surdos queremos", os avanços e desafios da educação de surdos aqui no Rio Grande do Sul. Em homenagem, eu estava com a mesma camiseta do $\vee$ Congresso Latino-Americano de Educação Bilíngue para Surdos (Foto 12).

Fonte: Arquivo pessoal.

\section{Foto 12 - Na UNIPAMPA em Santana do Livramento/RS (2009)}

Descrição da imagem: foto tirada na UNIPAMPA em Santana do Livramento/RS, no ano de 2009, no evento Dez anos da carta "A educação que nós surdos queremos". Na foto, eu estou de pé, sentada à mesa a Márcia Lunardi e ao lado a Madalena Klein, de costas as pessoas da plateia.

Foi um evento marcante, pois a prefeitura de Porto Alegre já havia inaugurado a Escola Municipal de Ensino Fundamental de Surdos Bilíngue Salomão Watnick, que até os dias de hoje está em funcionamento, atendendo surdos no Ensino Fundamental e na educação de jovens e adultos (EJA). Na época, eu ministrava aulas de Cultura Surda e Libras na Universidade do Vale do Rio dos Sinos (UNISINOS) e na Escola Municipal de Ensino Fundamental Especial para Surdos (EMEES) na cidade de Gravataí; 


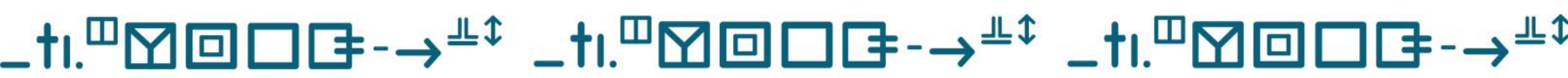

Memórias, histórias e narrativas da liderança surda na luta pela cidadania: da semente plantada à árvore crescida

Ana Luiza Paganelli Caldas

posteriormente, assumi o cargo de professora na escola municipal Salomão Watnick, sendo a primeira professora surda desta escola.

Procurei retomar a história e contar os fatos que aconteceram a partir de 1999 para aqueles que não conhecem a história do povo surdo. Mostrei imagens e ficaram admirados. Agradeço à intérprete por sua expressão e posicionamento, pois eu percebi que assistiram a palestra atentos. Concordo com Maria Cristina que, até agora, não existiam publicações que fizessem referência à nossa comissão do Rio Grande do Sul, que mostrassem fotos das pessoas que atuaram na passeata.

Faço homenagem especial nesse artigo às pessoas da comissão que fizeram nossa história da passeata ser valorizada até hoje.

É importante o registro em fotos e vídeos principalmente para as crianças surdas que ainda não sabem ler o português. As imagens são a marca da semente que foi crescendo e virou uma árvore no Brasil, disseminando força e informação.

O V Congresso Latino-Americano de Educação Bilíngue nos trouxe a sementeira de novas perspectivas, novos rumos alcançados: leis, acessibilidade, intérpretes em faculdades. Hoje, eu vejo, no Brasil, o lugar especial que ocupa o curso de Letras: Libras em vários estados, tendo sido pioneira, na criação desse curso, a Universidade Federal de Santa Catarina (UFSC), que disseminou a ideia. Além dele, também há os cursos técnicos de Institutos Federais.

Em busca de mais conhecimento, aproveitei uma visita à casa da minha irmã que mora em São Paulo e combinei com uma amiga surda que me levou até a cidade de Cotia/SP para visitar o Centro de Educação para Surdos Rio Branco, da Fundação Rotarianos de São Paulo. Fomos pela manhã. Percebi cinco professores surdos e ouvintes e fiquei admirada por 


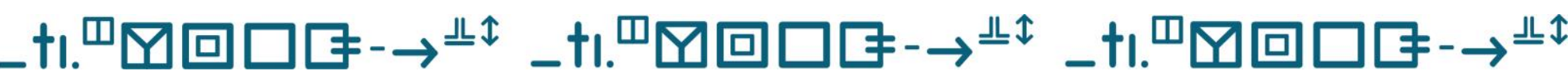

Memórias, histórias e narrativas da liderança surda na luta pela cidadania: da semente plantada à árvore crescida

Ana Luiza Paganelli Caldas

todos se comunicarem em Libras. Fui observar outra sala de quinta série e fiquei surpresa, pois um aluno surdo já fazia perguntas com alto nível de proficiência em Libras, e me contou que viu na televisão os nomes de jogadores do Brasil. Eu e minha amiga, antigamente, não nos comunicávamos igual a ele, por isso é necessário incentivar a aprender a Libras como primeira língua.

A professora ouvinte me perguntou onde eu morava. Respondi que sou do Sul, de Porto Alegre. Ela me disse que lembrou de mim, que veio a Porto Alegre, em 1999 e estava no V Congresso Latino-Americano Bilíngue de surdos. Ela então contou uma pequena história que começou a ensinar as crianças primeiro em língua de sinais e marcou a semente em 1999. Ela participou dessa virada para a comunicação em Libras com alunos surdos, aprendendo e evoluindo nos conteúdos escolares. Ficou marcada a história do V Congresso Latino-Americano Bilíngue de Surdos. Também contei que, na época, eu participava do curso de extensão com a professora pesquisadora Adriana da Silva Thoma (In memoriam), que procurou debater sobre "Memórias, Narrativas e Experiências Docentes na Educação de Surdos", evento que foi realizado pela Faculdade de Educação da Universidade Federal do Rio Grande do Sul (FACED/UFRGS) em 2008.

Podemos dizer que este trabalho foi uma importante sequência do movimento de 1999. Participaram colegas, ex-colegas de professores de surdos e professores surdos. O objetivo era trocar cartas através de um blog, tornando públicas nossas experiências e ideais de educação para surdos, ressaltando a história de educação de surdos, o que sofremos e o que superamos (THOMA, KLEIN, 2010). Esse trabalho no blog era realizado pela professora Adriana desde 2008. No curso, a dinâmica foi de sortear o colega remetente para escrever a carta e poderíamos colocar fotos. Em uma aula, a 


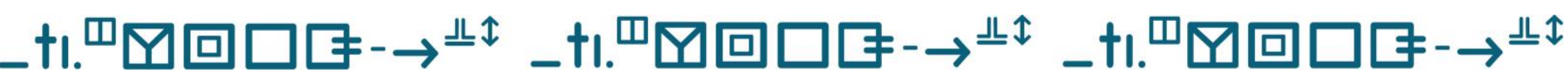

Memórias, histórias e narrativas da liderança surda na luta pela cidadania: da semente plantada à árvore crescida

Ana Luiza Paganelli Caldas

professora Adriana Thoma (In memoriam) solicitou que os alunos a autorizassem a dizer o nome dos colegas sorteados ao ler a narrativa escrita. Fiquei admirada em quantas histórias lindas e cativantes, todas públicas no blog até hoje.

A colega que eu tirei no sorteio trabalhava no Centro Municipal de Educação dos Trabalhadores (CMET) Paulo Freire, na época escola de Educação de Jovens e Adultos (EJA) surdos. Escrevi, na época do curso da professora Adriana Thoma, que admirava seu trabalho e seu esforço em aprender Libras, sempre estudando, fazendo cursos, mas não para interpretar e sim para aprender a língua. Também ela tinha maravilhosas ideias didáticas para trabalhar a totalidade $1^{2}$, um grupo com bastantes dificuldades, alguns com problemas neurais, outros cadeirantes; e ela atendia a todos com carinho, estabelecendo uma relação afetiva importante para a educação, trazendo como referência principal a comunicação em Libras, ensinando aqueles que não conheciam e também aqueles que já conheciam a Libras.

A professora Adriana me tirou no sorteio e me contou na carta a sua história. Ela relata que era concursada pela Prefeitura de Porto Alegre e trabalhava no CMET Paulo Freire. Quando ela saiu, eu fui chamada. Já estava esperando há quatro anos, quase terminando o prazo de validade do concurso, quando fui chamada para assumir seu lugar. Fiquei muito agradecida e logo comecei meu trabalho na Prefeitura de Porto Alegre.

Em 2006, fui chamada em um concurso da prefeitura e nomeada para trabalhar no CMET Paulo Freire, onde fiquei por 2 anos, até ser nomeada na UFRGS. Para assumir na UFRGS, precisei sair do município e da outra UNISC. Desses

\footnotetext{
${ }^{2}$ Totalidade 1 representa as séries iniciais da Educação de Jovens e Adultos (EJA).
} 


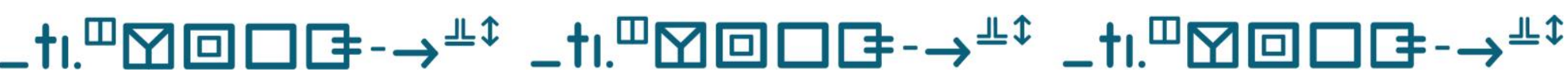

Memórias, histórias e narrativas da liderança surda na luta pela cidadania: da semente plantada à árvore crescida

Ana Luiza Paganelli Caldas

\begin{abstract}
dois lugares guardo muitas lembranças boas. Neles aprendi muito sobre a educação em geral e a educação de surdos, em particular. Do CMET, saí feliz porque sabia que você seria chamada para assumir. Você deve lembrar que foram dias de grande expectativa, tanto para você como para mim e para toda a escola, que queria muito a tua entrada lá (THOMA, 2008).
\end{abstract}

Esse curso de extensão foi uma marca importante dos acontecimentos após 1999, pois conseguimos visualizar muitas experiências de histórias com oralização, negligenciando a Libras, experiências ruins de inclusão escolar, narrativas marcadas pelo uso de aparelhos porque antigamente não havia nenhuma legislação que amparasse o uso da Libras. As práticas oralistas que forçam o surdo a falar sem o uso da Libras causaram muitos traumas, porque são baseadas em modelos ouvintistas de educação. Forçar a oralização sem usar a Libras traumatiza a aprendizagem do português, porque não entendemos o significado da voz. É um processo muito diferente. Hoje a Libras é o nosso modelo.

Percebemos nas respostas dessas lideranças surdas, um comprometimento que se estabelece entre seus membros, formando uma rede de trocas de comunicação, símbolos, imagens e outros dispositivos de identificação. Essa rede constitui-se através de um comprometimento com a Língua de Sinais, com a Cultura surda e as estratégias de compreender e relacionar-se com outros indivíduos surdos e com o mundo (THOMA; KLEIN, 2010, p.125).

Essas referências históricas estão presentes em artigo publicado pelas professoras Adriana da Silva Thoma e Madalena Klein (2010). O registro realizado no blog pela professora Adriana, das memórias e experiências narradas nas cartas através do curso de extensão citado, foi uma realização de muito sucesso e teve várias edições, que podem ser lidas no site 


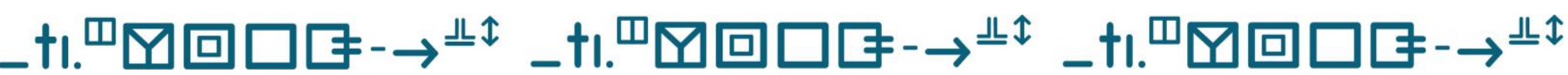

Memórias, histórias e narrativas da liderança surda na luta pela cidadania: da semente plantada à árvore crescida

Ana Luiza Paganelli Caldas

"Educação de Surdos - Memórias e Narrativas"3. São experiências verdadeiras, que falam de política linguística, de educação, de saúde; todas são marcas da comunidade surda, procurando garantir principalmente a segurança da escola para o surdo em Libras.

\section{Novos ramos}

Cada árvore plantada é um desafio novo. O esforço pela educação bilíngue ainda é importante. Sabemos que alunos surdos sozinhos incluídos nas escolas regulares, às vezes, sofrem limitações e não conseguem contato com seus pares crianças ou com professores, porque não possuem a Libras.

A escola ouvinte não conhece a Pedagogia Surda, que trabalha com conteúdos da história do movimento surdo, da cultura, da literatura e da arte surda, além das disciplinas ministradas em Libras.

A escola precisa trabalhar conteúdos sobre a identidade surda, mostrando fotos e filmes, incentivando a aquisição da Língua de Sinais Brasileira, a Libras. Hoje temos a plataforma Youtube, que possui uma forte divulgação de canais em Libras. Também, continua a referência do encontro comunitário nas Associações de Surdos.

A aquisição da identidade surda representa cultura; na escola inclusiva, não existe cultura surda. Lembro de quando eu trabalhava na escola de surdos, vinha um professor de Capão da Canoa conhecer e estudar temas sobre a surdez para ensinar uma aluna surda que dizia não ser surda. Claro, sua referência eram os ouvintes, pois não conhecia a Libras. Algumas pessoas ouvintes podem pensar que a comunicação em Libras é limitada.

\footnotetext{
3 THOMA, A. Site Educação de Surdos - memórias e narrativas. 2008. Disponível em: http://memoriasnaeducacaodesurdos.blogspot.com/. Acesso em: 07 dez. 2021.
} 


\section{_t..}

Memórias, histórias e narrativas da liderança surda na luta pela cidadania: da semente plantada à árvore crescida

Ana Luiza Paganelli Caldas

Percebo que alguns ouvintes falam extensamente, mas não constituem argumentos em Libras de maneira completa. Então, a informação que essa aluna tinha em Libras era parcial e não era muito significativa.

Preocupa-me que sujeitos surdos não participem de escolas bilíngues, não conheçam as associações de surdos, porque sua família também não conhece, porque os governos nos iludem com propostas de inclusão escolar que não respeitam nossa língua nativa.

Hoje temos muitas leis que apoiam nossa comunidade e garantem nossos direitos linguísticos. Não estamos diminuindo, nem morrendo, mas a proposta de inclusão escolar nos afasta da aquisição linguística na idade apropriada, fundamental para uma vida plena.

A criança precisa ser alfabetizada na sua língua nativa, para que possa entender o intérprete. Sabemos que é impossível, na escola inclusiva, o intérprete falar direto em Libras, pois as crianças surdas não entendem. Precisa adaptar a alfabetização para a primeira língua em Libras desde bebês, e assim as crianças vão desenvolver rápido e a família deve aprender a Libras para também melhorar as trocas familiares. Se a escola é de surdos, a tendência é aumentar as trocas sociais.

Existem várias possibilidades e materiais diversos para trabalhar a cultura surda. Todos os dias, em diferentes tipos de materiais visuais disponíveis na internet, têm informações que auxiliam na criação/educação das crianças surdas. Mas cultura surda não se cria sentado em casa! É importante sair para a rua, participar de associação de surdos, encontrar seus pares e lutar pelos seus direitos.

É importante chamar a atenção para a nossa união e, enquanto cultura surda, olhar para a própria vida e fortalecer o sentimento de comunidade 


\section{_t..}

Memórias, histórias e narrativas da liderança surda na luta pela cidadania: da semente plantada à árvore crescida

Ana Luiza Paganelli Caldas

numa relação que possibilite criar segurança para as pessoas, para que as pessoas surdas se sintam em casa no seu país.

Um dos problemas que nós tínhamos antes de 1999 era a oralização, pois nos obrigavam a falar, sem reconhecerem a Libras, limitando nossa comunicação. O movimento de 1999 ajudou a desenvolver a comunidade surda e vários artigos e leis foram publicados desde então. Nosso direito linguístico foi reconhecido e também foram reconhecidos os direitos do intérprete de Libras-português. Não resta dúvida de que esta passeata foi a semente plantada e germinada na nossa terra que não tem fronteira, de um povo que não tem limite geográfico (PERLIN; QUADROS, 2006).

Os acontecimentos históricos de 1999, em Porto Alegre marcaram a cultura surda do nosso país. O pré-congresso, o $\vee$ Congresso LatinoAmericano de Educação Bilíngue para Surdos e a passeata organizados pela comunidade surda junto com a FENEIS e NUPPES/UFRGS, que criou o documento $A$ educação que nós surdos queremos, foi a pauta inicial para o surgimento de leis e crescimento da comunidade surda.

Hoje temos pesquisas importantes vinculadas às teorias com temas sobre o movimento surdo, o espaço de luta e resistência surda, que trazem novamente o significado do desenvolvimento da prática da política, da cultura e da educação surda, inseridos no grande debate dos Estudos Culturais em Educação e Estudos Surdos, afastando cada vez mais a prática educativa e a cultura surda do discurso clínico sobre a surdez, em que médicos acreditam que o uso de aparelhos e implantes cirúrgicos são as soluções para ouvir. 


\title{
_t..
}

Memórias, histórias e narrativas da liderança surda na luta pela cidadania: da semente plantada à árvore crescida Ana Luiza Paganelli Caldas

\begin{abstract}
Os Estudos Surdos se constituem enquanto um programa de pesquisa em educação, onde as identidades, as línguas, os projetos educacionais, a história, a arte, as comunidades e as culturas surdas são focalizadas e entendidas a partir da diferença, a partir de seu reconhecimento político. [...] 0 Conceito de diferença não é utilizado como um termo a mais, dentro de continuidade discursiva, onde habitualmente se incluem outros como, por exemplo, "deficiência" ou "diversidade". Estes, no geral, mascaram e neutralizam as possíveis consequências políticas, colocam os outros sob um olhar paternalista, e se revelam como estratégias conservadoras para ocultar uma intenção de normalização. A diferença, como significação política, é construída histórica e socialmente; é um processo e um produto de conflitos e movimentos sociais, de resistências às assimetrias de poder e de saber, de outra interpretação sobre a alteridade e sobre significado dos outros no discurso dominante (SKLIAR, 1998, p. 5-6 apud DALL'ALBA, 2013, p. 21).
\end{abstract}

O SURDO OUVE EM LIBRAS. Por isso é importante o resgate histórico do movimento surdo nas áreas da educação, da cultura, do lazer, do esporte, da política. Hoje temos representantes surdos em várias áreas da sociedade.

É muito importante registrar a formidável história do documento que escrevemos sobre "A educação que nós surdos queremos", que foi marco na luta dos surdos e podemos continuar acrescentando mais outros documentos.

No ano de 2012, a lei de oficialização da língua completou dez anos, a comunidade surda organizou uma grande manifestação em Brasília no dia que a lei foi oficializada - 24 de abril. O objetivo da manifestação dos dez anos da Lei de Libras foi alavancar a luta pela implantação das escolas bilíngues aos surdos no Brasil (DALL'ALBA, 2013, p. 28).

Hoje a internet apresenta para as pessoas surdas inúmeras possibilidades de comunicação e acesso a informações. A comunicação pela internet 


\section{_t..}

Memórias, histórias e narrativas da liderança surda na luta pela cidadania: da semente plantada à árvore crescida

Ana Luiza Paganelli Caldas

trouxe independência e agilidade para os surdos, facilitando o acesso às informações e registro da cultura surda nas comunidades das redes sociais. Nós estamos engajados em uma nova rede de interações. É preciso continuar atentos para as novas possibilidades de divulgar a Língua de Sinais e as Associações de Surdos do país. A internet é o meio onde podemos promover manifestações políticas e afirmar a diferença surda para a sociedade ouvinte. A tecnologia é nosso apoio para consolidar a cultura e a língua dos surdos (CALDAS, 2012).

\section{Considerações finais}

É importante olhar para trás e nunca esquecer nossas marcas de mãos vivas em Libras. Precisamos continuar lutando pelo movimento surdo, cultivando uma rede de trocas de informações e de comunicação aproveitando a eficiência e rapidez da tecnologia (WhatsApp, Youtube, Facebook, E-mailetc.). É muito importante que surdos ou ouvintes sinalizem em Libras os vídeos para divulgar aos surdos.

Preocupa-me o fato de os alunos surdos estarem diminuindo nas escolas de surdos, pois estão isolados nas escolas de inclusão. Também nas Associações de Surdos a participação é pouca; as escolas de surdos devem apresentar a Associação para os alunos e famílias encontrarem os amigos surdos. Não posso acreditar que os surdos não participem de nada da sociedade, diminuindo e desaparecendo.

Passamos anos à frente com as Leis sobre Libras desde o ano de 1999, em 2002 e 2005 com o marco da Lei Federal. Hoje as leis são um ponto positivo, mas é preciso chamar a atenção de todos os surdos para a importância do laço de pertencer à cultura surda, de olhar a própria vida dentro da comunidade e da cultura surda criando possiblidades de se 


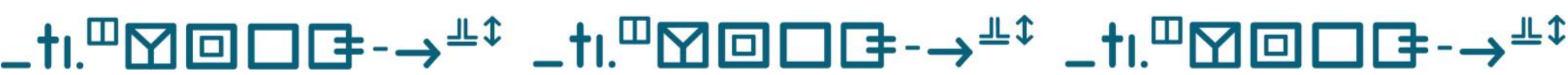

Memórias, histórias e narrativas da liderança surda na luta pela cidadania: da semente plantada à árvore crescida

Ana Luiza Paganelli Caldas

relacionar com as pessoas de um jeito igual, com respeito à nossa diferença, valorizando a língua de sinais como recurso seguro e método de compreensão das relações sociais com outros indivíduos e com o mundo, bem como valorizar as parcerias com Escolas e Universidades.

Continuamos a plantar sementes e a expandir nossa cultura, buscando visibilidade no cenário nacional. Conquistamos o espaço acadêmico do ensino superior, temos pessoas surdas que são professores, mestres e doutores. O Rio Grande do Sul foi modelo para outras regiões do Brasil, mas ainda há muito o que ser feito. Temos pouca informação sobre o espaço das Escolas de Surdos e Associações. Precisamos chamar nossos pares para continuar formando grupos, o momento é de criação contínua. Esse momento que narrei marcou minha vida e a de muitas outras pessoas surdas que se tornaram fortes lideranças numa comunidade unida por falar a mesma língua. Às vezes, o tempo faz esquecer, mas eu busquei as fotos que registraram esse momento e agora compartilho neste artigo, como forma de agradecimento a todos da comunidade que participaram, aos políticos que receberam nossas propostas fortalecendo nossas reivindicações.

Uma proposta de trabalho para as novas gerações da comunidade surda, junto com a FENEIS, as Associações de Surdos, as Escolas de Surdos, as famílias de surdos: organizar na sua cidade passeata geral nacional dia 26 de setembro, todos os anos.

Novas gerações precisam engajar na luta e contribuir para o fortalecimento e para a ampliação das escolas bilíngues para surdos. 


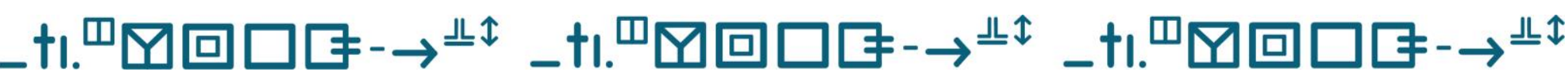

Memórias, histórias e narrativas da liderança surda na luta pela cidadania: da semente plantada à árvore crescida

Ana Luiza Paganelli Caldas

\section{Referências}

CALDAS, A. L. P. Movimento Surdo: Identidade, língua, cultura. In: PERLIN, G.; STUMPF, M. (Orgs.). Um olhar sobre nós surdos: leituras contemporâneas. Curitiba: Editora CRV, 2012. p. 139-147.

DALL'ALBA, C. Movimento Surdo e Educação: Negociação de Cultura Surda. 2013. 94 f. Dissertação (Mestrado em Educação) - Programa de PósGraduação em Educação, Universidade Federal de Santa Maria, Santa Maria, 2013. Disponível em: <https://repositorio.ufsm.br/bitstream/handle/1/7063/DALL\%20ALBA\%2C\% 20CARILISSA. pdf?sequence=1\&isAllowed=y>. Acesso em: 10 fev. 2019.

FENEIS. A educação que nós surdos queremos. 1999. Disponível em: $<$ https://pt.scribd.com/document/54492509/A-EDUCACAO-QUE-NOSSURDOS-QUEREMOS>. Acesso em: 18 fev. 2019.

FERNANDES, S.; MOREIRA, L. C. Políticas de educação bilíngue para surdos: o contexto brasileiro. Educar em Revista, Curitiba, n. spe-2, p. 51-69, 2014. Disponível em: $\quad<$ http://www.scielo.br/scielo.php?script=sci arttext\&pid=S0104-40602014000600005\&Ing=en\&nrm=iso>. Acesso em $26 \mathrm{fev}$. 2019.

FERRAZ, R. de A. O Mundo Surdo: Passeata dos Surdos - luta e comemoração. 2009. Monografia (Especialização em Educação Especial: Estudos Surdos), Faculdade Santa Helena, Recife, Pernambuco, 2009. Disponível em: $<$ http://www.educacao.pe.gov.br/portal/upload/galeria/750/monografia rafael a ferraz.pdf>. Acesso em: 27 fev. 2019.

GOÉS, C. Informação verbal. [fev. 2019]. Entrevista cedida a Ana Luiza Paganelli Caldas. Porto Alegre, 2019).

MARTINS, C. R. Informação verbal. [fev. 2019]. Entrevista cedida a Ana Luiza Paganelli Caldas. Porto Alegre, 2019.

MÖRSCHBÄCHER, E. G. Informação verbal. [fev. 2019]. Entrevista cedida a Ana Luiza Paganelli Caldas. Porto Alegre, 2019.

PERLIN, G.; QUADROS, R. M. de. Ouvinte: o outro do ser surdo. In: QUADROS, R. (Org.). Estudos Surdos I, Petrópolis, RJ: Arara Azul, 2006, p. 166-185. Disponível em: <https://www.editora-arara-azul.com.br/ParteA.pdf>. Acesso em: 10 fev. 2019.

PERAZZOLO, G. Informação verbal. [fev. 2019]. Entrevista cedida a Ana Luiza Paganelli Caldas. Porto Alegre, 2019.

PEREIRA, M. C. P. Informação verbal. [fev. 2019]. Entrevista cedida a Ana Luiza Paganelli Caldas. Porto Alegre, 2019.

THOMA, A. Site Educação de Surdos - memórias e narrativas. 2008. De Adriana para Ana Luiza. Disponível em: 
